\title{
Academic integrity matters: five considerations for addressing contract cheating
}

\author{
Erica J. Morris(iD
}

\author{
Correspondence: \\ dr.erica.morris@gmail.com \\ Independent Consultant, Milton \\ Keynes, Buckinghamshire, UK
}

\begin{abstract}
This commentary paper examines the issue of contract cheating in higher education, drawing on research and current debate in the field of academic integrity. Media coverage of this issue has reflected significant concerns in the field about students' use of custom academic writing services, along with sector and national calls for action that would lead to making such essay mills illegal. However, recent studies have revealed the complex nature of contract cheating, with a relatively low proportion of students engaging in outsourcing behaviours involving a third party. This paper focuses on how universities and colleges can respond to this emergent concern, and proposes that institutions extend and establish strategies to embed the values, principles and practices aligned to academic integrity. As part of this endeavour, five areas of consideration are offered for higher education institutions that relate to: determining academic integrity strategy; reviewing institutional policy; understanding students; re-visiting assessment practices; and implications for staff professional development.
\end{abstract}

Keywords: Academic integrity policy, Contract cheating, Professional development, Assessment

\section{Introduction}

This commentary focuses on the issue of contract cheating in higher education. In recent years, international work in the field of academic integrity has turned to examining this issue, including looking at the nature of contract cheating, estimating the prevalence of the problem, uncovering contributory factors or reasons as to why a student may outsource their assignment to a third party, and exploring how higher education institutions can effectively respond by enhancing both academic integrity policy and educational approaches (Bretag \& Harper, 2017; Bretag et al., 2018; Curtis \& Clare, 2017; Harper et al., 2018; Lancaster \& Clarke, 2016; Newton \& Lang, 2016). Contract cheating is a term that is now well-established in the literature to refer to 'the outsourcing of student work to third parties' (Lancaster \& Clarke, 2016, p. 639) and is typically used to describe a related set of practices in which students make use of third-party services, particularly academic custom writing services or essay banks, or where friends, family, other students or private tutors create an assignment, which a

(c) The Author(s). 2018 Open Access This article is distributed under the terms of the Creative Commons Attribution 4.0 International License (http://creativecommons.org/licenses/by/4.0/), which permits unrestricted use, distribution, and reproduction in any medium, provided you give appropriate credit to the original author(s) and the source, provide a link to the Creative Commons license, and indicate if changes were made. 
student then submits as their own (Lancaster \& Clarke, 2016; Newton \& Lang, 2016; Walker and Townley, 2012).

Empirical investigations have been vital for this area of academic integrity. Significant concerns have been raised by national agencies for assuring standards in higher education about students' use of third-party services for assessment purposes (Bretag et al., 2018; Quality Assurance Agency [QAA], 2017). Media coverage has mirrored these concerns (e.g. McKie, 2018), but it could be argued that news stories simplify the issue, which is clearly complex, or could be seen as alarmist in approach. However, recent reports on how the use of EduBirdie has been promoted by media stars in YouTube channels for music, dating and gaming (e.g. Jeffreys \& Main, 2018) has drawn attention to the international concern that there are students who are making use of essay mills, and that such services were not immediately and readily seen as a serious issue for students by those outside of higher education (in which influencers on YouTube refer to, for example, 'professional nerds' or 'a bunch of ... nerds to do the work for you'). Indeed, a government minister is cited on how such activity is 'clearly wrong because it is enabling and normalising cheating potentially on an industrial scale' (Jeffreys \& Main, 2018). This raises the question of how in higher education we might respond.

Throughout higher education, it is crucial that academic integrity is promoted and re-asserted through international and national initiatives, and institutional policy and practice. By drawing on recent work that has enhanced our understanding of the issue of contract cheating, higher education institutions can focus on continuing to develop institutional strategy for academic integrity. This paper identifies five considerations for universities and colleges that are particularly relevant to this endeavour, including how the issue of contract cheating can be addressed: determining academic integrity strategy; reviewing institutional policy; understanding students; re-visiting assessment practices; and implications for staff professional development.

\section{Determining academic integrity strategy}

Over the last decade, a consensus has emerged that a holistic or multi-pronged strategy is required for higher education institutions to promote and support academic integrity, and effectively address its 'shadow' - student academic misconduct, particularly plagiarism, collusion and contract cheating (Bertram Gallant, 2008; Sutherland-Smith, 2008; Bretag et al., 2013; Higher Education Academy [HEA], 2010; HEA, 2011; Morris, 2016). Such a strategy should have an educational emphasis, fostering students' developing academic literacies; ensuring professional development for staff relating to academic integrity education, applying policy, and enhancing curriculum (e.g. re-designing assessment); and be aligned to institutional policy for managing student academic misconduct, which is informed by recommendations or evidence-informed frameworks for implementing policy (e.g. Bretag \& Mahmud, 2016; Morris \& Carroll, 2016).

A holistic approach is still pertinent and appropriate for addressing the issue of contract cheating, but as proposed by Bretag and Harper (2017), there is a need for higher education institutions to ensure a 'systemic approach', in which academic integrity is integral to the wide range of institutional activity and processes, including: student recruitment, orientation and induction; policy and procedures; teaching and learning practices; working with students; the professional development of staff; and 
the use of technology (e.g. text-matching software). It is essential that in-depth consideration is given by institutions as to how they can integrate and augment their institutional strategy or approach with regard to all forms of student academic misconduct, including the outsourcing of assessment to third parties. For example, in the UK, national guidelines and recommendations have included the need to:

'establish a cross-institutional group or committee, supported by senior management, involving representatives from all faculties ... university services ... and student representation with a remit from promoting academic integrity across the institution ... and reviewing the policy and related guidance' (HEA, 2011, p. 8).

The implication here is that this kind of oversight can involve bringing together and building on the variety of measures and educational activities in place to provide a coherent institutional approach that is relevant to contemporary concerns. For example, questions could be asked about how the institution's teaching, learning and assessment strategy is connected to the academic integrity or student academic misconduct policy, or how visible and accessible this policy is for all stakeholders, including students and the range of staff roles. Morris and Carroll (2016) have pointed to the need for stakeholders to appreciate that typically, there are no straightforward solutions in responding to academic integrity issues. Further, the implementation of a holistic approach must be applicable and responsive to the institutional context, with implementation entailing institutional resources to be committed and significant time for institutional change to be realised (Morris and Carroll, 2016). Therefore, an essential starting point for change is a review of existing institutional policy and procedures for academic integrity matters. To determine priority areas for development, this process can be accompanied by an institutional review of associated resources and activity, such as materials for student induction, forums for academic integrity champions, or toolkits for academic staff on designing assessment.

\section{Reviewing institutional policy}

A wealth of resources to support a process of review and implementation of policy and procedures are available for universities and colleges, including a conceptual framework, good practice recommendations and tools ${ }^{1}$ (Bretag \& Mahmud, 2016; Bretag et al., 2011). Regarding the issue of contract cheating, it has been argued that as part of a multi-pronged strategy at an institution, 'a focus on the positive issues of academic integrity may prevent and/or deter students from using ... third parties' (Newton \& Lang, 2016, p. 265). Based on an extensive analysis of institutional policies, Bretag and her colleagues recommended that one of the core elements of exemplary policy, specified as 'Approach', should not only frame academic integrity in terms of an 'educative process', but that:

'There is a clear statement of purpose and values with a genuine and coherent institutional commitment to academic integrity through all aspects of the policy' (Bretag et al., 2011, p. 7).

This is pertinent to all forms of student academic misconduct, including contract cheating. Institutions might draw on existing definitions of academic integrity to agree 
and build a shared understanding of commitment across the staff and student body, for example:

'Academic integrity means acting with the values of honesty, trust, fairness, respect and responsibility in learning, teaching and research. It is important for students, teachers, researchers and all staff to act in an honest way, be responsible for their actions, and show fairness in every part of their work. Staff should be role models to students.' (Exemplary Academic Integrity Project, 2013).

However, policy must be understood, 'brought to life' (see Morris \& Carroll, 2016) and be positioned by a central academic integrity office (or equivalent), so that the policy (and any associated changes from a review process) can have an impact on addressing misconduct. Findings from a recent survey of staff working in Australian universities has pointed to the value of policy, with a relatively high proportion of staff (51\%) agreeing that policies and processes help to minimise contract cheating (Harper et al., 2018).

Through the regular review of policy, universities and colleges can make sure that there is detail available on all forms of student academic misconduct, in which a 'definition for each needs to be clear with a range of realistic examples that take into account the varied forms of assessment used within different discipline areas' (HEA, 2011, p. 17). Policy frameworks should also include guidance and tools to support decision-making in determining appropriate penalties. There have long been concerns about the consistency of procedure in managing cases of student academic misconduct, particularly with regard to decision making in determining the seriousness of a breach and the associated penalty (e.g. Tennant \& Duggan, 2008; Yeo \& Chien, 2007). Clearly, 'inequitable treatment is intrinsically unfair' (Ibid., 2007, p. 187).

In the UK, against a backdrop of concern that there was inter-institutional variation across the sector in the use of penalties for plagiarism, and through a national research exercise, a Plagiarism Reference Tariff was produced (iParadigms Europe, 2009-11). This might be adopted by an institution to determine appropriate penalties or as a tool for benchmarking their own regulations under review. Under this tariff a 'submission purchased from [an] essay mill or ghost-writing service' can lead to one of a set of five penalties (which penalties to be applied is also dependent on factors, such as the student's level of study) - two of which refer to expulsion from the institution (with credits retained or withdrawn). More recently in the UK, the QAA have stressed how contract cheating is essentially a 'special case' of student academic misconduct, which is:

'an extremely serious matter because the deliberate, intentional decision of a student to engage a third party to complete work ... elevates the seriousness of contract cheating above what would normally apply to a case of plagiarism. The recommended sanction ... should be suspension or expulsion' (QAA, 2017, p. 26).

Harper and her colleagues (2018) report on the main types of penalties for cases of contract cheating as identified through a survey of staff at Australian universities. These included a range of responses from not knowing (28\%), a warning or counselling (42\%), 
a reduced mark (28\%), resubmission (27\%) and zero awarded for the assignment (37\%), with only a minority of staff indicating that the penalty of suspension or exclusion/ expulsion were applied ( $4 \%$ and $2 \%$ respectively). These researchers urge that for cases of contract cheating penalties should be 'of an appropriate severity if they are to serve as disincentives for students to engage in this behaviour' (Harper et al., 2018, p. 120). Institutional guidance may also need to be revised to address a potential concern for students: what are they to do if they suspect or have evidence of a peer or group of peers engaging in contract cheating? From the perspective of the student, this could be a difficult dilemma (the peer may be a friend or flat mate). Recent proposals for institutional strategy include ensuring students feel able to report their concerns, are supported in doing so (Ellis, Zucker \& Randall, 2018) and that policy includes 'safeguards for false accusations and protection of individuals raising concerns' (QAA, 2017, p. 21).

To assess the impact of changes to policy or related programmes of activity, such as academic integrity campaigns or initiatives in the longer term, it is vital that institutions have measures in place to record and monitor academic integrity issues (Bretag et al., 2011; Bretag and Mahmud, 2016; HEA, 2011). These perspectives have recognised that a centralised system holding records about breaches, which is maintained by the institution, can be helpful in developing a clear picture or patterns in relation to the different forms of student academic misconduct (and possible changes over time), as well as in identifying issues concerning whether penalties are consistently applied (in line with institutional regulations). Through analysis, such records can also be used to indicate whether there are particular areas, such as subjects or modules where, for example, there may be a relatively high occurrence of a particular form of academic misconduct. With this latter possibility, there can then be a consideration of how an educational intervention, for instance, might be valuable for a specific context (Bretag and Mahmud, 2016; HEA, 2011). The Quality Assurance Agency (QAA) in the UK have encouraged institutions to maintain detailed records on academic misconduct, differentiating between contract cheating and other forms to enable institutions to evaluate whether responses to address contract cheating are effective (QAA, 2017).

\section{Understanding students}

Consideration has been given to estimating the proportion of students engaging in contract cheating. There has been caution that media coverage about the numbers of students making use of third-party services 'can appear ... overblown' (Curtis \& Clare, 2017, p. 116), but as suggested by these authors, it is important that policy makers have an awareness of the prevalence of contract cheating. Well-informed perspectives are valuable to mitigate assumptions that many students are readily seeking a third party to complete their assessments for them. There are methodological challenges in building a reliable and representative picture relating to the prevalence of the different types of contract cheating. This is primarily because evidence is usually derived from self-report, with the recognition that individuals may not accurately report on their own tendencies and behaviours, as well as the difficulty of capturing the range of possibilities with regard to engaging third parties (Curtis \& Clare, 2017; Newton \& Lang, 2016). 
Recent work has indicated that a low proportion of students engage in contract cheating: in a meta-analysis of findings from five studies, Curtis and Clare (2017) conclude that $3.5 \%$ of students report that they have engaged in this form of cheating, and in a large-scale survey, it was found that $2.2 \%$ of respondents reported that they had obtained a completed assignment to submit as their own (Bretag et al., 2018). However, this survey investigated a range of outsourcing behaviours, finding that $5.8 \%$ of respondents reported that they engaged in one or more of the five forms of cheating, including submitting an outsourced assessment, providing exam assistance and arranging for someone else to take an exam.

In addition to ascertaining the likely extent of contract cheating, it is also valuable to gain further insight on the reasons that might lead a student to seek, use and/or return to using third party services. In dealing with academic dishonesty, Brimble (2016) offers clarity:

'there are a variety of motivations that may drive student behavior resulting in a complex web of situational, behavioral, and contextual issues that educators and education managers need to understand in order to put strategies in place to manage this dilemma' (Brimble, 2016, p. 367).

Similarly, Bertram Gallant (2008) explored dimensions relevant to explanations of student academic misconduct, including internal (i.e. the characteristics of the student), organisational (i.e. what goes on with fellow students and in learning settings) and institutional (i.e. academic context). The established understanding in the field of academic integrity is that student academic misconduct is due to a variety of contributory factors, including students' attitudes, motivations, preferences and prior experiences, that are likely to mix with, and be linked to, contextual and wider societal influences (Bertram Gallant, 2008; Brimble, 2016).

One of the key matters at hand is that contract cheating relates to a number of outsourcing behaviours, which have been extensively considered as an 'outsourcing spectrum' ranging from two defined 'sharing behaviours' to five 'cheating behaviours' (Bretag et al., 2018; Harper et al., 2018). This work has advanced our understanding of the factors that are linked to whether a student may outsource their assignment to a third party. To investigate the role of such factors, this recent work compared survey findings in relation to a group of respondents who had engaged in one or more of the cheating behaviours with those respondents that were categorised as a 'non-cheating group' (Bretag et al., 2018). Through such analysis, these researchers have identified that, in relation to this latter group, students in the 'cheating group' had lower levels of agreement in responding to aspects about the teaching and learning environment, such as 'understanding assessment requirements', 'receiving sufficient feedback' and 'opportunities to approach educators'. Specifically, the key factors identified as significantly related to the likelihood of 'cheating behaviours' are 'students' International or LOTE (Language Other than English at home) status, higher levels of dissatisfaction with the teaching and learning environment, and perceptions that there are lots of opportunities to cheat' (Ibid., pp. 10-11). Findings also shed light on how students, who may engage in outsourcing their assignments, are tending to rely on peers, friends or members of their family, rather than making use of services offered through websites (Bretag, et al., 2018). 
Curtis and Clare (2017) point out that the possibility that a student may turn to using third party services is likely to be related to motivational factors as well as potential opportunity. Leading commentators have emphasised how custom writing services are established businesses, easily found online and advertising to students through, for example, business cards or fliers (Newton \& Lang, 2016; Lancaster \& Clarke, 2016). Further, such websites offer a range of services to produce different forms of assessment (e.g. dissertations, case studies, lab reports) at affordable prices and within short time scales. There is the possibility that features of these websites are 'persuasive'. Adopting a usability framework to assess particular dimensions of websites, such as judged credibility or user involvement, Rowland and her colleagues (2018) identified how the eleven 'contract cheating' websites they reviewed, included a number of features relevant to a credibility dimension (e.g. content assuring qualified writers, confidentiality) and an involvement dimension (e.g. live chat, 24/7 help facility). Such websites also have conflicting messages for students. ${ }^{2}$ These findings have implications for academic integrity strategy in universities and colleges: How are we talking to students about the problem of these services and of contract cheating? In what ways can we enable staff within institutions to ensure effective discussions with students about this issue?

The idea of the 'vulnerable' student has been put forward, who is essentially under pressure and may, for example, be more readily persuaded by the information on custom essay writing websites (Rowland et al., 2018). But it could be valuable to take a different angle: lines of enquiry or investigations could consider those students who undertake good academic practice in completing their assessment tasks - What are the key factors that influence their behaviour? How do they respond to pressures (internal and external)? What do they do that makes a difference?

\section{Re-visiting assessment practices}

In the evolving field of academic integrity, perspectives have consistently emphasised the importance of enhancing assessment practices as a key part of institutional strategy for academic integrity (e.g. Macdonald \& Carroll, 2006; Morris, 2016; Sutherland-Smith, 2008). Good practice guidance for institutions has included advice on re-designing assessment to minimise opportunities for student academic misconduct, primarily focused on student plagiarism. However, although good practice guidelines for assessment are often based on evidence (e.g. Gibbs \& Simpson, 2004) assessment strategies assumed to address academic integrity issues have, in the main, not be the subject of studies evaluating their effect or impact on student attitudes or behaviour (or the possible reduction in incidences of student plagiarism). Widely cited strategies have emerged, such as changing assessment tasks each year or assessing the process of developing an assignment, as well as the final output (e.g. Hrasky \& Kronenberg, 2011).

With the growing recognition that third-party services could be employed by students for all kinds of tasks (e.g. critical reflections, lab reports) and can be delivered quickly to students (e.g. within a day), recommendations have been offered to prevent the use of custom writing services (Newton \& Lang, 2016; Lancaster \& Clarke, 2016). These include, for example, oral assessments in the form of in-class or recorded presentations, interviews or vivas, or seminar debates (see also Joughin, 2010). It has also been necessary to question commonly held ideas relating to how assessment 
design is a key solution to contract cheating (Bretag \& Harper, 2017): for instance, 'personalised, sequential and original assessments' will not necessarily prevent this form of academic misconduct as, in principle, any form of assessment (or aspects of an assignment) can be outsourced. Informed by the outcomes of a project on contract cheating and assessment design, valuable advice and guidance assets have been produced for the higher education sector. ${ }^{3}$ These resources explore the underpinnings of the problem of contract cheating, with suggested actions for institutions, educators and students. For example, in the guidance 'Managing risk for different assessment types', seven types of assessment strategies are re-visited that are relevant to the issue (e.g. in-class assessment, vivas) and are evaluated in the light of risk (for outsourcing behaviours) and advantages in terms of student learning.

Across higher education over the last decade, there has been a focus on improving assessment practices within universities and colleges through using evidence-informed frameworks and methodologies, with national and institutional projects undertaken to transform assessment policy and practice (e.g. Boud and Associates, 2010; Ferrell, 2013; HEA 2012; Jessop \& Tomas, 2017). This is an area that institutions should continue to progress. In the light of academic integrity concerns about the outsourcing of assessment, it is recommended that institutions ensure that students understand what is required in assignments, and that they receive sufficient feedback to learn from that work' (Bretag et al., 2018, p. 14). The idea of developing assessment literacy is valuable in this regard, in which establishing a community of practice for staff and students is necessary for facilitating a shared understanding of assessment standards within subject, discipline or professional areas (HEA, 2012; Price et al., 2012). Assessment literacy includes developing an understanding of how assessment relates to learning and the assessment process, a grasp of the nature and meaning of assessment criteria and standards, and building skills in self- and peer-assessment (Price et al., 2012). In practice, assessment literacy might be fostered through the implementation of an assessment protocol for staff and students, and integrating activities in curriculum that involve students constructing, discussing and applying assessment criteria, and using exemplars (see Anglia Ruskin University, 2018). Essentially, this approach can help students to understand what is expected and required of them through active participation, opportunities to prepare for assessments (e.g. in-class discussion about an assignment brief) and the process of formative feedback.

\section{Implications for staff professional development}

With regard to the issue of contract cheating, two key implications for staff professional development are clear: the need for good practice guidelines to assist staff in identifying the possibility of contract cheating, and guidance on how to facilitate effective discussions with students about academic integrity issues. Recent survey findings indicate that many staff think that contract cheating is 'impossible to prove' (57\%) and/or may not feel they are supported by senior management about this matter (Harper et al., 2018). However, these researchers highlight that cases of contract cheating can be pursued effectively in institutions, but institutions may not necessarily be ensuring that all relevant staff engage with the issue or are not always communicating aspects about the process for referring cases or the outcomes from these cases. 
A sustainable institutional strategy must involve a full consideration of how staff can be kept informed of contemporary academic integrity concerns, such as contract cheating, and how academic integrity champions or specialists across an institution (e.g. working at the subject or departmental level) can disseminate working knowledge of process and enable the sharing of good practice in identifying possible academic integrity breaches. Rogerson (2017) offers a practical process linked to the assessment cycle of preparing, marking and evaluating tasks, which involves identifying, recording and investigating irregularities that may be due to a student outsourcing their work. For example, while marking a student assignment, irregularities can be considered and documented; these are indicative signals relating to, for instance, the content (e.g. not addressing the assignment question) or referencing (e.g. using irrelevant sources). This evaluative approach is refreshing as it is tied to interactions with students:

'Explanations can then be sought from the student as to why the observations appear the way they do ... Conversations ... enlighten us and provide opportunities to ... evaluate learning practice and differentiate between contract cheating and poor academic writing skills' (Rogerson, 2017, p. 12).

A recurring theme in the current literature is the importance, in teaching and learning environments, of building relationships with students and holding discussions with them about academic integrity issues (Bretag et al., 2018; Ellis et al., 2018; Rogerson, 2017; Rowland et al., 2018). For example, there are specific suggestions for educators about how they might talk with students about academic writing services, such as the meaning of the help that these websites offer, so that educators can ensure students are fully aware of the sources of support at their institution (Rowland et al., 2018). An institutional approach should develop ways to support staff practices to talk with students about this issue of concern.

\section{Conclusions}

It is a deeply concerning that academic writing services are widely available and that a small minority of students are turning to a third party to produce their assignments. Recent reports on how EduBirdie, for example, has essentially been promoted in social media platforms continue to heighten concerns about the extent of contract cheating. There is, however, a need to remain cautious of claims that the incidence of contract cheating is increasing, as little baseline data is available to support this. Such investigations on a potential increase would also be confounded by the complexity of contract cheating and changes in the field about how the problem is understood (e.g. a number of different student outsourcing behaviours have been established). On this note, based on their meta-analysis, Curtis and Clare (2017) report that they 'did not find any clear evidence of a historical trend for contract cheating to be more prevalent' (p. 123).

This paper has offered five areas of consideration that are pertinent for an institutional response to the issue of contract cheating. There must be continued international work to emphasise that academic integrity matters: over the last ten years, there is much that higher education institutions have focused on to develop policy for student academic misconduct and improve teaching, learning and assessment practices. With the issue of contract cheating taking centre stage in the academic integrity debate over 
recent years, it is clear that institutions will need to continue to review and develop existing policy and procedures. Furthermore, such work should be part of an integrated institutional academic integrity strategy, which a university or college determines through building on their existing approach, with students and staff working in partnership on shared aims and principles.

In international scholarship (Draper et al., 2017; Newton \& Lang, 2016) and at sector and national levels (Bretag \& Harper, 2017), there are calls to introduce legislation, so that it is illegal to advertise or offer contract cheating services (QAA, 2016). This would be in line with legislation in New Zealand and the recent publication in Ireland of the Amendment Bill for Qualifications and Quality Assurance (Education and Training), which gives the national agency, Quality and Qualifications Ireland 'statutory powers to prosecute "essay mills" and other forms of academic cheating' (Department of Education and Skills, 2018). In the UK, there is currently a petition to Government to "Ban the provision and advertising of "essay mill" cheating services,', with current endorsement of this petition expressed by, for example, a senior leader at an institution (Smith, 2018). It is generally recognised that if such services were illegal, this could help to provide a clear and consistent message to students about their use. Legislation could therefore solve aspects of the issue of contract cheating. It is vital, however, that universities and colleges extend and establish strategies to embed the values, principles and practices aligned to academic integrity. Further, it may well be worth exploring a protocol for academic integrity for the higher education sector at an international level, building on the ideas for a universal code of expectations and practices (Stuhmcke et al., 2016).

\section{Endnotes}

${ }^{1}$ Resources available from the Exemplary Academic Integrity Project website. www.unisa.edu.au/EAIP.

${ }^{2}$ For example, on the Edubirdie website, it is stated: 'If you can't write that essay, EduBirdie can' and at the bottom of the 'What is EduBirdie?' page on the website the following is given: 'it may be tempting to use the content we provide you as your own work, but we advise you to please use our services responsibly. The content ... should serve only as a guide for your work and not the final product.' https://uk.edubirdie.com/ what-is-edubirdie.

${ }^{3}$ Resources available from the Cheating and Assessment Design project website. www.cheatingandassessment.edu.au.

${ }^{4}$ Petitions. UK Government and Parliament. Ban the provision and advertising of 'essay mill' cheating services. https://petition.parliament.uk/petitions/227277.

Abbreviations

HEA: Higher Education Academy; LOTE: Language Other than English; QAA: Quality Assurance Agency

Acknowledgements

Non applicable.

Funding

Non applicable.

Availability of data and materials Non applicable. 
Author's contribution

The article has been authored solely by Erica J. Morris.

\section{Authors' information}

EJM is a Principal Fellow of the Higher Education Academy (HEA), with leadership experience in higher education assessment strategy and systems, and academic integrity policy and practice. EJM has recently led the Degree Standards project focused on strengthening the external examining system in the UK, was an invited expert for a Roundtable and National Speaking Tour in Australia for the Exemplary Academic Integrity project (2013) and led the Academy JISC Academic Integrity Service in the UK (2009-11). With an interdisciplinary background in psychology, technology-enhanced learning and statistical education, EJM has worked at Anglia Ruskin University and the Open University, UK.

\section{Competing interests}

The author declares that they have no competing interests.

\section{Publisher's Note}

Springer Nature remains neutral with regard to jurisdictional claims in published maps and institutional affiliations.

Received: 24 October 2018 Accepted: 29 November 2018

Published online: 27 December 2018

References

Anglia Ruskin University (2018) Anglia Assessment Album. https://www.anglia.ac.uk/anglia-learning-and-teaching/goodteaching-practice-and-innovation/assessment-and-feedback/assessment-protocol. Accessed 18 Oct 2018

Bertram Gallant T (2008) Academic Integrity in the Twenty-First Century: A Teaching and Learning Imperative. In: ASHE Higher Education Report 33(5). Wiley Periodicals, Inc., San Francisco

Boud D, Associates (2010) Assessment 2020: seven propositions for assessment reform in higher education. Australian Learning and Teaching Council, Sydney

Bretag T, Harper R (2017) Addressing contract cheating: local and global responses. Project on Contract Cheating and Assessment Design: Exploring the Connection PowerPoint presentation https://cheatingandassessmenteduau/ publications-presentations/ Assessed 18 Oct 2018

Bretag T, Harper R, Burton M, Ellis C, Newton P, Rozenberg P, Saddiqui S, van Haeringen K (2018) Contract cheating: a survey of Australian university students. Stud High Educ. https://doi.org/10.1080/03075079.2018.1462788

Bretag T, Mahmud S (2016) A conceptual framework for implementing exemplary academic integrity policy in Australian higher education. In: Bretag T (ed) Handbook of academic integrity. Springer, Singapore, pp 463-480

Bretag T, Mahmud S, Wallace M, Walker R, James C, Green M, East J, McGowan U, Partridge L (2011) Core elements of exemplary academic integrity policy in Australian higher education. Int J Educ Integrity 7(2):3-12

Bretag T, Mahmud S, Wallace M, Walker R, McGowan U, East J, Green M, Partridge L, James C (2013) 'Teach us how to do it properly!' An Australian academic integrity student survey. Stud High Educ. https://doi.org/10.1080/03075079.2013.777406

Brimble M (2016) Why students cheat: an exploration of the motivators of student academic dishonesty in higher education. In: Bretag T (ed) Handbook of academic integrity. Springer, Singapore, pp 365-382

Curtis GJ, Clare J (2017) How prevalent is contract cheating and to what extent are students repeat offenders? J Acad Ethics 15:115-124

Department of Education and Skills (2018) 21 July, 2018 - Minister Mitchell O'Connor announces the publication of the Qualifications and Quality Assurance (Education and Training) (Amendment) Bill. https://www.education.ie/en/PressEvents/Press-Releases/2018-press-releases/PR18-07-21.html. Accessed 18 Oct 2018

Draper MJ, Ibezium V, Newton P (2017) Are essay mills committing fraud? An analysis of their behaviours vs the 2006 fraud act (UK). Int J Educ Integrity 13(3). https://doi.org/10.1007/s40979-017-0014-5

Edubirdie website. https://uk.edubirdie.com/. Accessed 18 Oct 2018

Ellis C, Zucker IM, Randall D (2018) The internal business of contract cheating: understanding the business processes and models of academic custom writing sites. Int J Educ Integr 14(1). https://doi.org/10.1007/s40979-017-0024-3

Exemplary Academic Integrity Project (EAIP) (2013) Embedding and extending exemplary academic integrity policy and support frameworks across the higher education sector. Plain English definition of academic integrity. Office for Learning and Teaching Strategic Commissioned Project 2012-2013. www.unisa.edu.au/EAIP. Accessed 18 Oct 2018

Ferrell G (2013) Supporting assessment and feedback practice with technology: from tinkering to transformation. Final synthesis report for the Jisc Assessment and Feedback programme. https://www.jisc.ac.uk/rd/projects/assessment-andfeedback. Accessed 18 Oct 2018

Gibbs G, Simpson C (2004) Conditions under which assessment supports students' learning. Learn Teach Higher Educ 1:3-31

Harper R, Bretag T, Ellis C, Newton P, Rozenberg P, Saddiqui S, van Haeringen K (2018) Contract cheating: a survey of Australian university staff. Stud High Educ. https://doi.org/10.1080/03075079.2018.1462789

HEA (2011) Policy Works: Recommendations for reviewing policy to manage unacceptable academic practice in High Educ The Academy JISC Academic Integrity Service. The Higher Education Academy, York https://www.heacademy.ac.uk/ system/files/policy_works_0.pdf. Accessed 18 Oct 2018

HEA (2012) A Marked Improvement: Transforming assessment in Higher Education. The Higher Education Academy, York https://www.heacademy.ac.uk/knowledge-hub/marked-improvement. Accessed 18 Oct 2018

Higher Education Academy (HEA) (2010) Supporting Academic Integrity: Approaches and resources for higher education. Academy JISC Academic Integrity Service, The Higher Education Academy, York, UK. https://www.heacademy.ac.uk/ knowledge-hub/supporting-academic-integrity-approaches-and-resources-higher-education. Accessed 18 Oct 2018

Hrasky S, Kronenberg D (2011) Curriculum redesign as a faculty-centred approach to plagiarism reduction. Int J Educ Integr $7(2): 23-36$ 
iParadigms Europe (2009-11) Plagiarism Reference Tarriff. https://www.plagiarism.org/assets/Tennant_referencetariff1506356085.pdf. Accessed 18 Oct 2018

Jeffreys B, Main E (2018) The YouTube stars being paid to sell cheating. BBC News. 1 May 2018. https://www.bbc.co.uk/news/ education-43956001. Accessed 18 Oct 2018

Jessop T, Tomas C (2017) The implications of programme assessment patterns for student learning. Assess Eval High Educ 42(6):990-999

Joughin G (2010) A short guide to oral assessment. Leeds Metropolitan University and the University of Wollongong Lancaster T, Clarke R (2016) Contract cheating: the outsourcing of assessed student work. In: Bretag T (ed) Handbook of academic integrity. Springer, Singapore, pp 639-654

Macdonald R, Carroll J (2006) Plagiarism - a complex issue requiring a holistic institutional approach. Assess Eval High Educ 31(2):233-245

McKie A (2018) There's clearly a demand; there's clearly a supply. Times Higher Education, 12 Sept 2018

Morris EJ (2016) Academic integrity: a teaching and learning approach. In: Bretag T (ed) Handbook of academic integrity. Springer, Singapore, pp 1037-1053

Morris EJ, Carroll J (2016) Developing a sustainable holistic institutional approach: dealing with realities 'on the ground' when implementing an academic integrity policy. In: Bretag T (ed) Handbook of academic integrity. Springer, Singapore, pp 449-462

Newton PM, Lang C (2016) Custom essay writers, freelancers, and other paid third parties. In: Bretag T (ed) Handbook of academic integrity. Springer, Singapore, pp 449-462

Price M, Rust C, O'Donovan B, Handley K, Bryant R (2012) Assessment Literacy. The Foundation for Improving Student Learning. Assessment Standards Knowledge exchange (ASKe). The Oxford Centre for Staff and Learning Development, Oxford

QAA (2016) Plagiarism in higher education. Custom essay writing services: an exploration and next steps for the UK higher education sector. The quality Assurance Agency for Higher Education www.qaa.ac.uk. Accessed 18 Oct 2018

Quality Assurance Agency (QAA) (2017) Contracting to cheat in higher education. How to address contract cheating, the use of third-party services and essay mills. The Quality Assurance Agency for Higher Education. www.qaa.ac.uk. Accessed 18 Oct 2018

Rogerson AM (2017) Detecting contract cheating in essay and report submissions: process, patterns, clues and conversations. Int J Educ Integrity 13(10). https://doi.org/10.1007/s40979-017-0021-6

Rowland S, Slade C, Wong KS, Whiting B (2018) 'Just turn to us': the persuasive features of contract cheating websites. Assess Eval High Educ 43(4):652-665

Smith A (2018) As a matter of fairness and social justice, we must ban essay mills. Times Higher Education 11 Oct 2018, p 29

Stuhmcke A, Booth T, Wangmann J (2016) The illusory dichotomy of plagiarism. Assess Eval High Educ 41(7):982-995

Sutherland-Smith W (2008) Plagiarism, the internet and student learning: Improving academic integrity. Routledge, New York and London

Tennant P, Duggan F (2008) AMBeR project. In: Academic misconduct benchmarking research project. Part 2. The recorded incidence of student plagiarism and the penalties applied. JISC and the Higher Education Academy, UK https://www. plagiarism.org/paper/academic-misconduct-benchmarking-research-project-part-2. Accessed 18 Oct 2018

Walker M, Townley C (2012) Contract cheating: a new challenge for academic honesty. J Acad Ethics 10:27-44

Yeo S, Chien R (2007) Evaluation of a process and proforma for making consistent decisions about the seriousness of plagiarism incidents. Qual High Educ 13(2):187-204

\section{Ready to submit your research? Choose BMC and benefit from:}

- fast, convenient online submission

- thorough peer review by experienced researchers in your field

- rapid publication on acceptance

- support for research data, including large and complex data types

- gold Open Access which fosters wider collaboration and increased citations

- maximum visibility for your research: over $100 \mathrm{M}$ website views per year

At BMC, research is always in progress.

Learn more biomedcentral.com/submissions 